\title{
INVESTIGATION ON THE BEHAVIOR OF RIGID POLYVINYLCHLORIDE PIPES SUBJECTED TO UNIAXIAL COMPRESSION LOADS
}

\author{
Abdullah Ali Nasser Alhamati, Abdul Halim Ghazali*, Jamalodin Norzaie, \\ Thamer Ahmed Mohammed, and Mohd Razali Abdul Kadir \\ Department of Civil Engineering, Faculty of Engineering, \\ Universiti Putra Malaysia, 43300 Serdang, Selangore, Malaysia
}

Received 08 November 2005

\begin{abstract}
The objective of this research was to investigate the capability of rigid Polyvinylchloride (PVC$\mathrm{U})$ pipes to sustain axial loads. The behavior of PVC-U pipes specimens subjected to short-term uniaxial compression loads were experimentally investigated. Results of the load-displacement tests on pipes of different wall thickness, diameter, and specimen heights were recorded. The experimental test results show that the PVC-U pipes are capable of supporting loads greater than the required design load $(3.4 \mathrm{kN})$. Increasing the pipe specimen height decreases the pipe strength for supporting the axial loads. Euler buckling was observed in the pipe specimens with small diameter and long axial height. Furthermore, an attempt has been made to utilize the ANSYS finite element commercial package to model the pipe system using eight noded brick element and the results were compared with those obtained from the experimental tests. Good agreement was found between the two sets of results, within the elastic range of the loaddisplacement curve.
\end{abstract}

Keywords: PVC-U pipes, polyvinylchloride, uniaxial load, models

\section{INTRODUCTION}

The long-term behavior of various Polyvinylchloride (PVC) products application has a good record of long-term durability [1,2]. The range of PVC's application demonstrates that this is the most versatile among thermoplastics [3]. The good performance and low cost of polyvinylchloride products make this polymer very suitable for applications in buildings, mainly in exterior applications, like sheet piles, window profiles, cladding structures and siding $[1,4]$.

The phenomenon of cylindrical tubes made from different materials (steel, aluminum, and PVC$\mathrm{U})$ and various geometrical shapes collapsing in axial compression is considered one of the most efficient means of crash energy absorption, and therefore their collapse behavior has been studied by many researchers [5 - 23].

The collapsing of PVC-U tubes under axial compression loads were investigated by some researchers for the purpose of crash energy absorption devices. For instance, Mamalis et al. 1986 [5] reported the crumpling of thin-walled PVC-U tubes when subject to axial load. They examined the tubes with external circumferential grooves. They reported non-axisymmetric

\footnotetext{
*Corresponding author e-mail: abdhalim@eng.upm.edu.my
} 
diamond mode of deformation. Later, Mamalis et al. 1986 [6] presented collapse mechanisms for the axial crumpling of thin-walled circular cones and truncated circular cones. Their experiments were carried out on shells made of PVC-U; their modes of failure and loaddeflection characteristics were determined. Mamalis et al. 1989 [7] also investigated theoretically and experimentally the axial collapse of thin-walled square tubes and frusta of PVC-U. The deformation modes and load-compression characteristics were reported and deformation mechanisms were proposed to describe the crumpling process of the shells. Singace 2000 [13] studied analytically and experimentally the collapse of axially crushed sawdust-filled PVC-U tubes. It was found that, empty PVC-U tubes normally collapse into multi-lobe mode when axially crushed but at a certain value of wood filler density, the collapse reverts from multi-lobe to concertina mode and therefore the overall energy absorption performance of the PVC-U tubes is enhanced.

In the present study, a commercial PVC-U pressure pipes available in the local market [24] were tested under a short-term uniaxial compression loads to investigate the strength of the pipes under axial compression loads. The main purpose of the test is to evaluate the capability of the pipe to be used as a subsurface water storage system, which is required to support an axial load of $3.4 \mathrm{kN}$, calculated based on the manuals of American Society of Civil Engineers 1992 [24]. The effect of different pipe wall thickness, diameter, and height on the pipe strength was investigated.

\section{MATERIALS AND METHODS}

\subsection{Materials and specimen preparation}

The thickness of the PVC-U pipes walls for pipe sizes chosen for the analysis are presented in Table 1. The heights of the pipe specimens for each diameter and thickness are $100 \mathrm{~mm}, 200$ $\mathrm{mm}, 300 \mathrm{~mm}, 400 \mathrm{~mm}, 500 \mathrm{~mm}$ and $600 \mathrm{~mm}$. Thus, total of 48-specimens of PVC-U pipes were tested in uniaxial compression. Some of the specimens prepared are shown in Fig. 1. The pipe specimen material was PVC-U. Details related to the material properties were provided by the manufacturer of the pipes [25] and are shown in Table 2.

Table 1: Dimension and thickness of $P V C-U$ pipes

\begin{tabular}{cc}
\hline External pipe diameter $(\boldsymbol{D}) \mathbf{( m m})$ & Pipe wall thickness $(\boldsymbol{t}) \mathbf{( m m})$ \\
\hline & 3.2 \\
\multirow{2}{*}{89.1} & 3.8 \\
& 5.0 \\
& 6.1 \\
\hline \multirow{3}{*}{114.3} & 4.0 \\
& 4.7 \\
& 6.4 \\
\hline
\end{tabular}

\subsection{Test procedure}

Each specimen was placed between parallel platens of an Instron 8500 digital-testing universal machine with a full-scale load range of $250 \mathrm{kN}$ (Fig. 2). The axial load was applied at a crosshead speed of $2 \mathrm{~mm} / \mathrm{min}$ until the specimen yield point was reached. The load146 
displacement curve for each specimen was recorded by an automatic data acquisition system. The temperature and the humidity during the tests were maintained $23^{\circ} \mathrm{C}$ and $50 \%$ respectively.

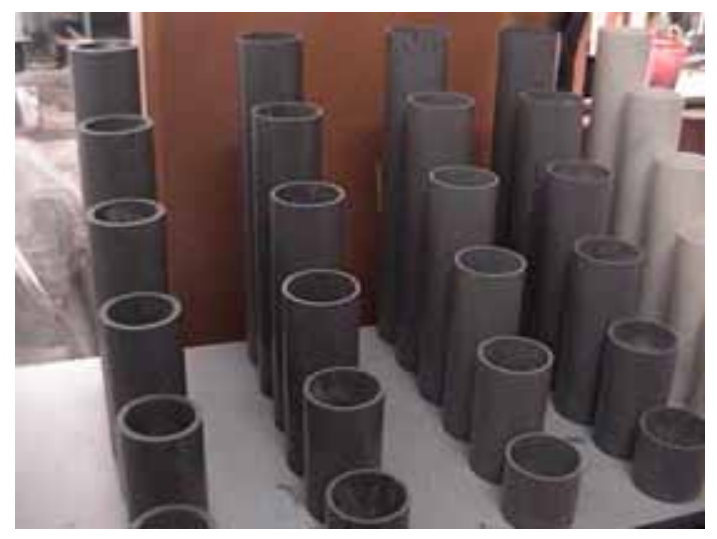

Fig. 1: Pipes specimens prepared for test

Table 2: Properties of PVC-U pipes

\begin{tabular}{lll}
\hline Property & Unit & Value \\
\hline Specific Gravity & - & 1.42 \\
Hardness & Rockwell R & 120 \\
Water Absorption & $\mathrm{mg} / \mathrm{cm}^{2}$ & 0.05 \\
Tensile Strength & $\mathrm{MPa}$ & 45 \\
Elongation at Break & $\%$ & 80 \\
Compressive Strength & $\mathrm{MPa}$ & 66 \\
Modulus of Elasticity & $\mathrm{MPa}$ & 2700 \\
Izod Impact Strength & $\mathrm{kJ} / \mathrm{m}^{2}$ & 6 \\
Poisson's Ratio & - & 0.37 \\
\hline
\end{tabular}

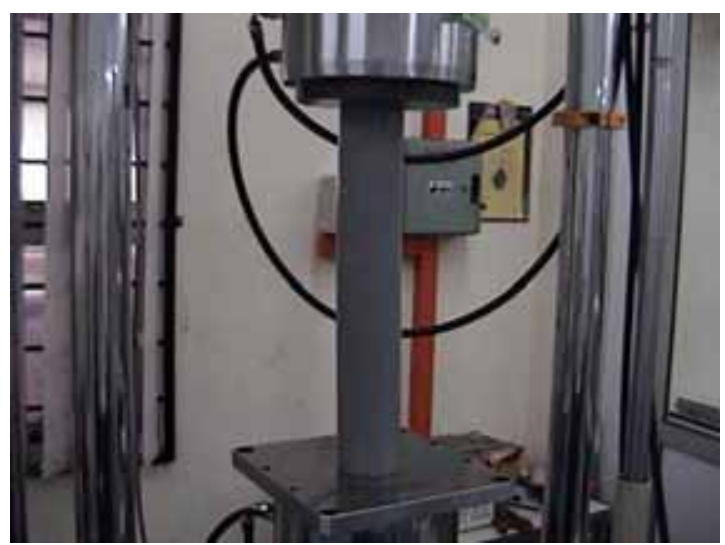

Fig. 2: Placement of a specimen on the testing machine 


\section{CLASSICAL FORMULAS FOR STRESS AND STRAIN}

Formulas for membrane stresses and deformations in thin-walled pressure vessels were used for predicting the stress and the displacement (deformation) of the pipes when subjected to an axial compression load. Young and Budyanas 2002 [26] presented many formulas for thin-walled pressure vessels for different cases to determine the membrane stresses and displacements. In this study the closest case may be applicable to the pipe test is shown in appendix A (Fig. A.1).

In the theoretical analysis the axial load of $3.4 \mathrm{kN}$ was applied on all the pipe specimens and the stresses, vertical displacements, and the radial displacements given by Equations (A.1), (A.2), and (A.3) in appendix A are calculated.
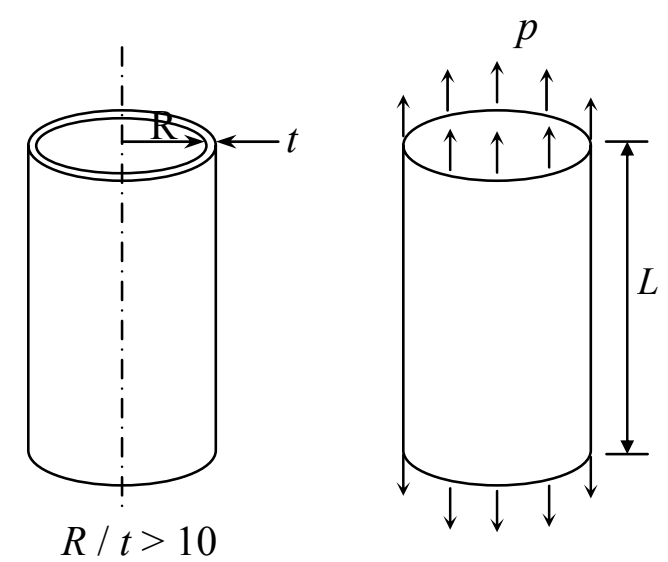

Fig. A.1: Cylindrical vessel under uniform axial load

\section{FINITE ELEMENT MODELING}

Finite Element Analysis (FEA) technique was used to determine the stresses and displacements for the pipes specimens. This technique was used due to the following reasons,

1. Equation (A.1) does not give the effect of the boundary condition at the pipe bottom on the stress distribution along the pipe.

2. To investigate the applicability of these equations for the pipe tests subjected to an axial compression load, as the equations are applicable for a cylindrical vessel subjected to an axial tension load.

3. To verify the effect of the ratio $R / t$ on the results because the equations can be used for the ratio of $R / t$ greater than 10 where some pipe specimens have ratio below this value.

Axial crushing of the PVC pipes was simulated using ANSYS Release 9.0 finite element code. In the analysis the model was fixed at one end (at the bottom) and uniformly distributed load was applied at the other end to simulate the testing condition (Fig. 3).

The pipe was modeled using Solid 3-D brick element available in the element library of the ANSYS commercial package called SOLID45 [27]. The entire pipe geometry is modeled with a relatively fine mesh to avoid distorted aspect ratios. A typical mesh is shown in Fig. 3.

The pipe was analyzed under different boundary conditions to investigate the condition that is close to the experimental tests of the pipe specimens, namely:

(a) All the bottom nodes are restrained against z-direction movement. 
(b) All the bottom nodes are restrained against the translation in $x, y$, and $z$ direction respectively.

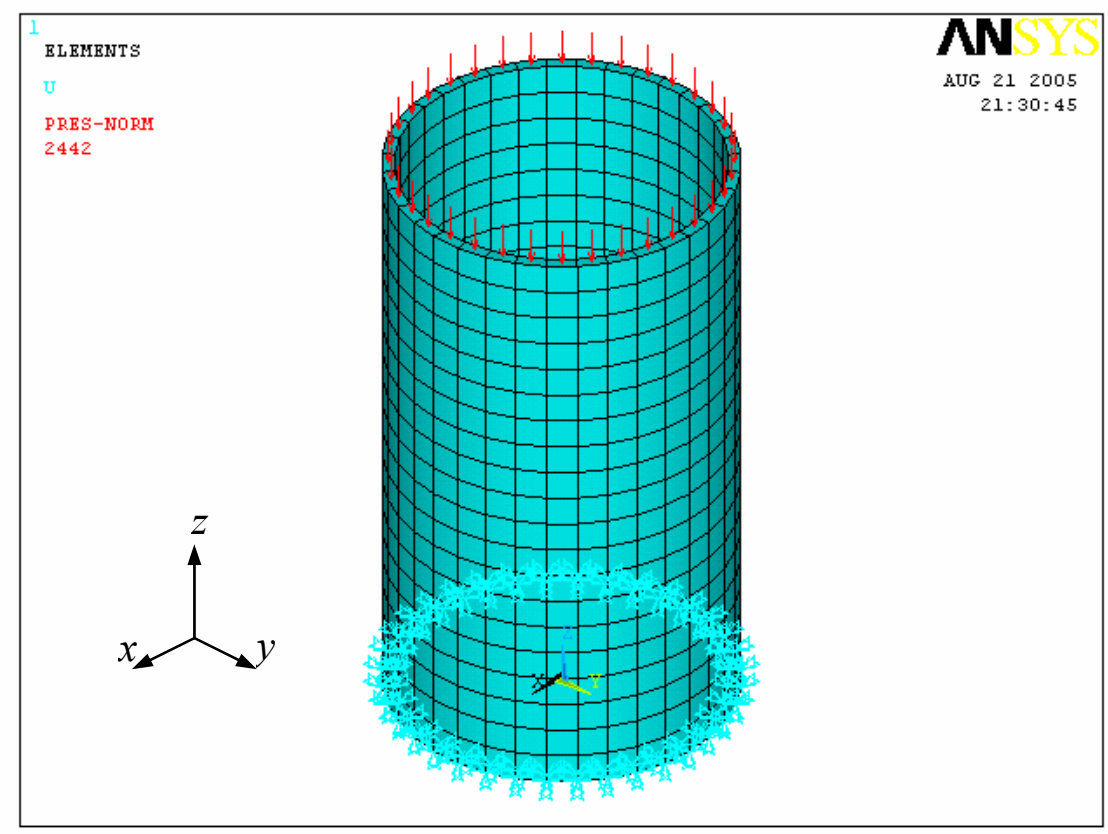

Fig. 3: Finite element modeling of pipe specimens

In the evaluation of the boundary condition, a pipe with $89.1 \mathrm{~mm}$ diameter, $3.2 \mathrm{~mm}$ wall thickness and $300 \mathrm{~mm}$ height is fixed first at the pipe bottom in the axial direction ( $z$ direction). The pipe was subjected to an axial compression load of $3.4 \mathrm{kN}$ (Figs. 4(a) and (b)). It was found that,

1. The stress distribution in $z$ direction $\sigma_{z}$ (maximum stress) along the pipe height is constant and no stress concentration at any point of the pipe (Fig. 4(c)).

2. There is a horizontal displacement in one direction of the pipe (Fig. 4(d)).

In the next test, the same pipe was tested again but the pipe bottom was fixed in all directions ( $x$, $y$ and $z$ ) as shown in Fig. 5(a). It was found that,

1. The stress distribution $\sigma_{z}$ is not constant along the pipe height and a maximum stress (stress concentration) developed at the bottom of the pipe. This indicates that the pipe failure may occur at this location. In addition, the stress at the pipe external wall is greater than the pipe internal wall stress at the pipe bottom, which means that a local buckling failure may be expected (Figs. 5(b) and (c)).

2. A very small horizontal displacement $(0.026 \mathrm{~mm})$ in a radial direction of the pipe is developed (Fig. 5(d)).

From the experimental tests on the pipes specimens, it was found that, most of the specimens failed at the bottom due to local buckling, and no horizontal displacement at one direction was observed on the pipe specimens. This illustrates that, the second case (b) (pipe bottom fixed in all directions) is closer to the experimental tests. 


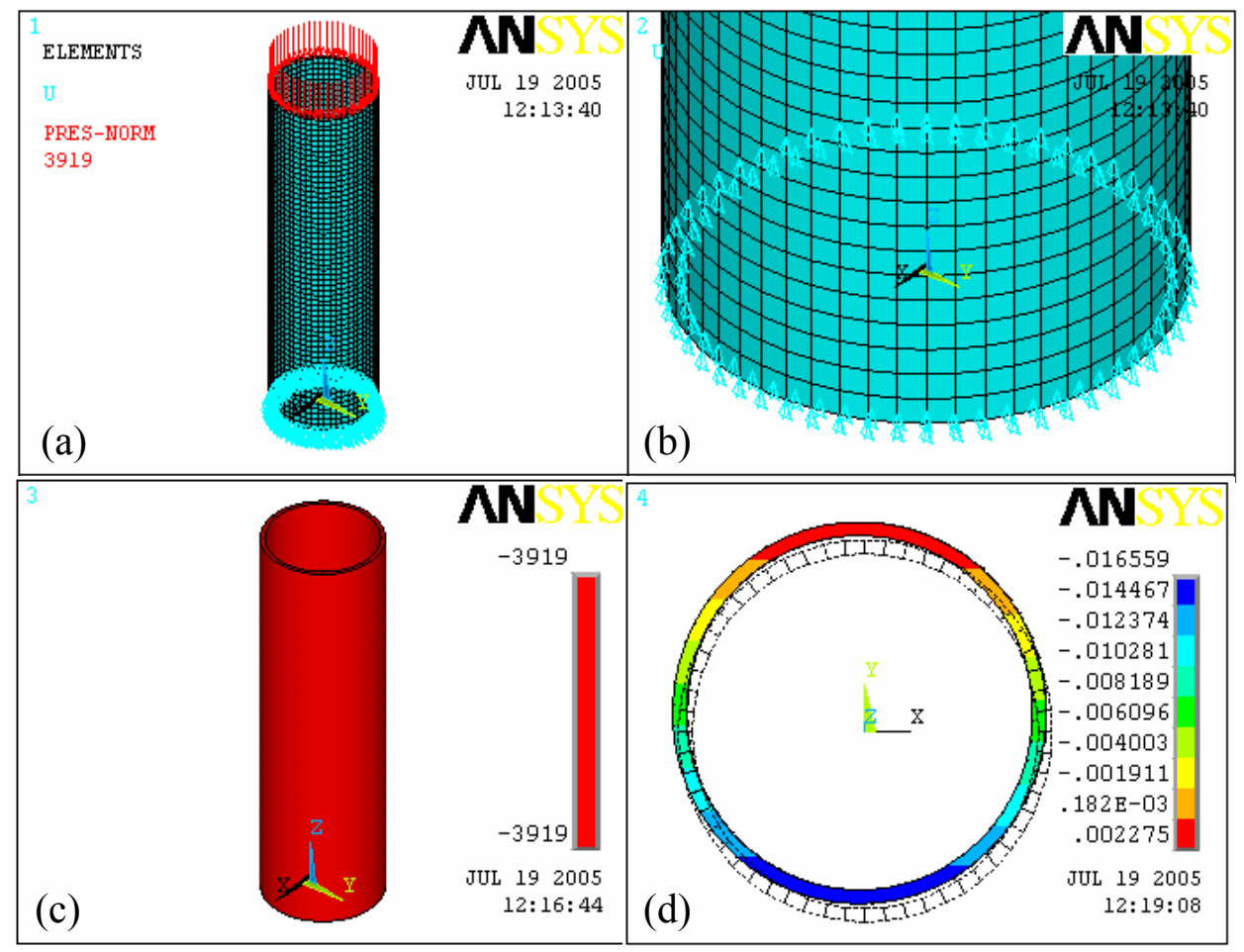

Fig. 4: Pipe fixed at the bottom in a vertical direction only, $z$
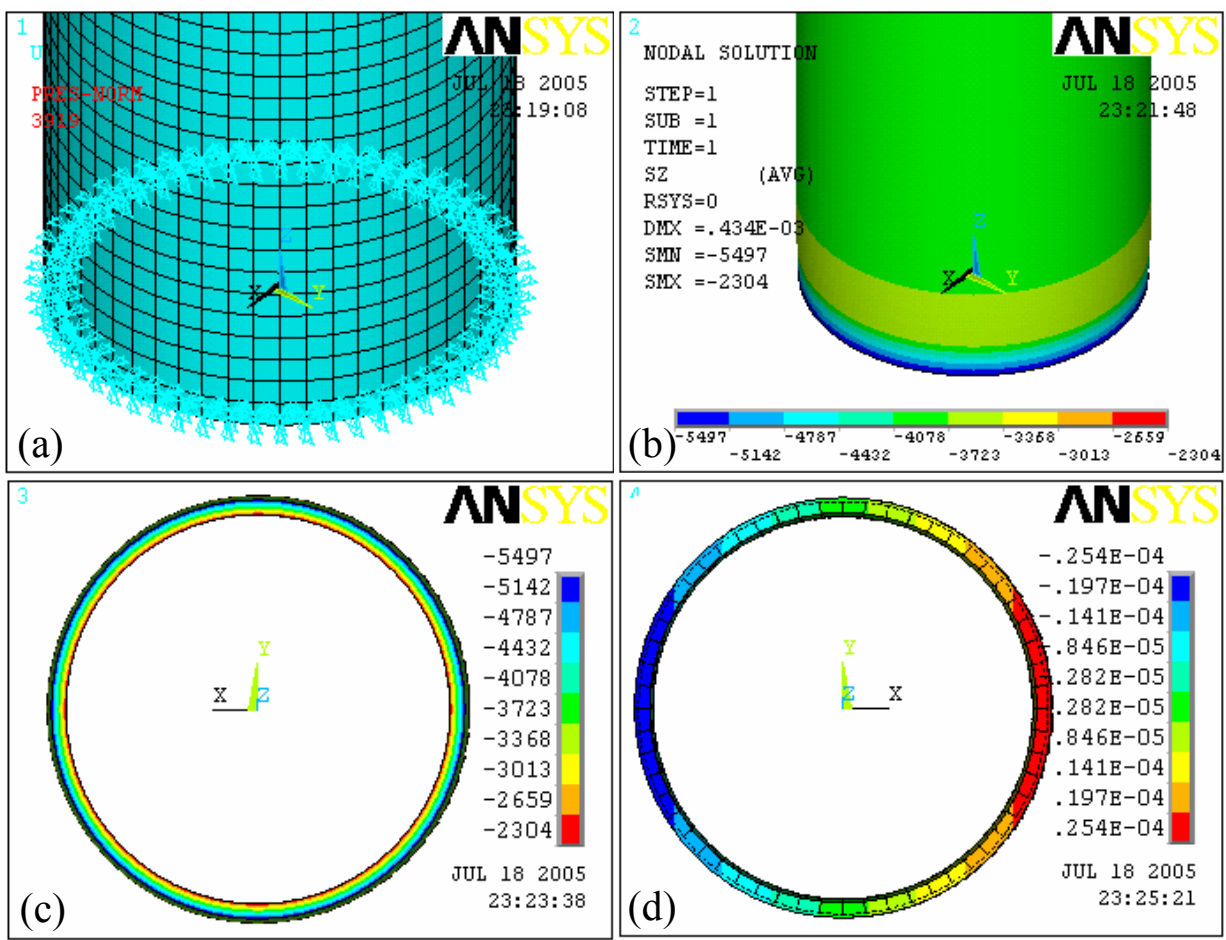

Fig. 5: Pipe fixed at the bottom in all directions

150 


\section{RESULTS AND DISCUSSION}

\subsection{Experimental results}

The behavior of the PVC-U pipes under uniaxial compression loads with different thicknesses, diameters, and heights are presented in Figs. 6, 7, 8, 9, and 10.

\subsubsection{Pipe of $89.1 \mathrm{~mm}$ diameter}

Figure 6 shows that, the maximum compression load of the pipe decreases by increasing the pipe height to an average value of $13 \%$ when the pipe height is increased from $100 \mathrm{~mm}$ to 600 $\mathrm{mm}$ and a maximum reduction value of $28 \%$ occur with pipe thickness of $3.2 \mathrm{~mm}$.

Load-displacement relationship for some selected specimens (3.2 mm pipe thickness) is presented in Fig. 7. The figure shows the effect of the pipe height in this relation. Euler buckling was observed with long pipe specimens $(500 \mathrm{~mm}$ and $600 \mathrm{~mm})$ as shown in Fig. 8.

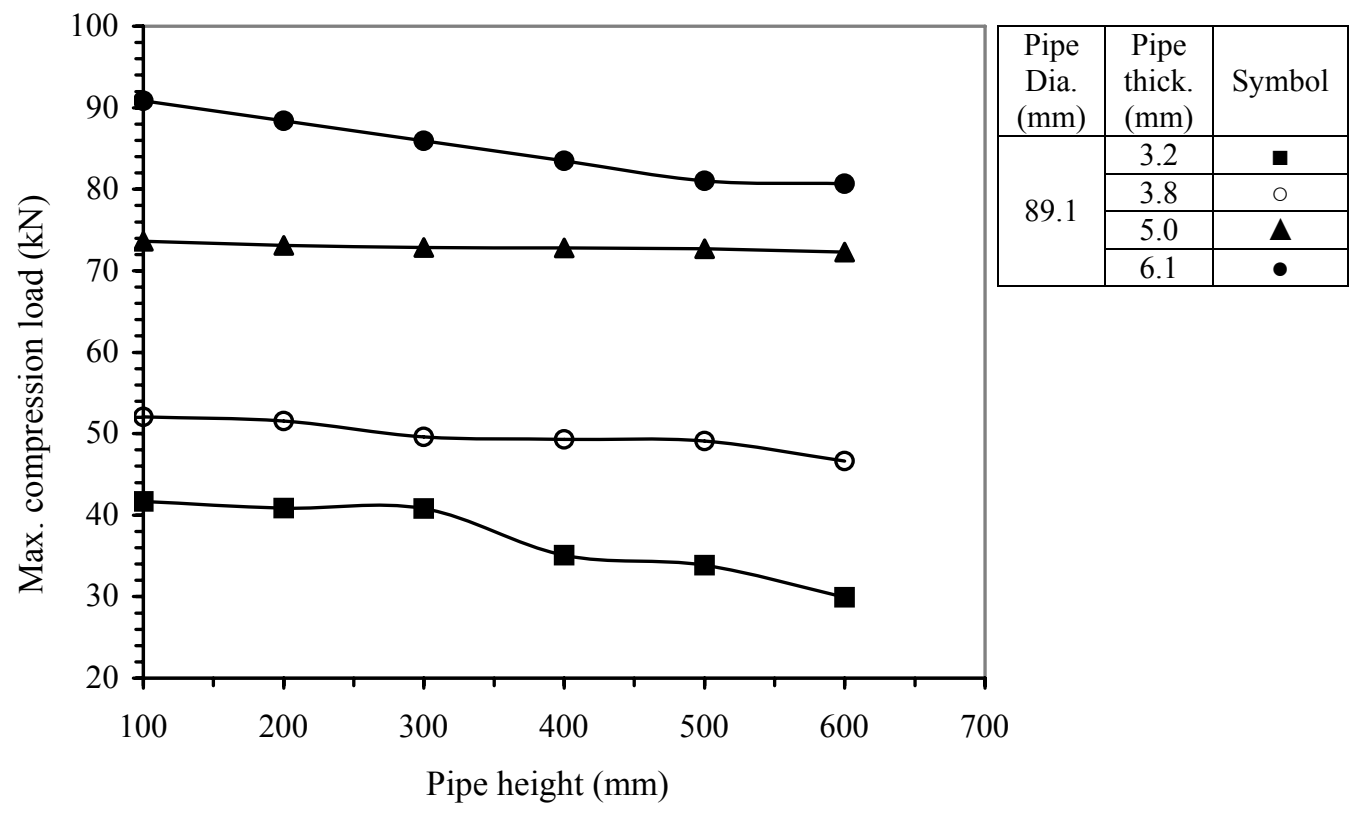

Fig. 6: Effect of the pipe height and thickness on the maximum compression load

\subsubsection{Pipe of $114.3 \mathrm{~mm}$ diameter}

Reduction of maximum pipe compression loads due to increasing pipe height was also observed in this pipe diameter but with lower observed values from the pipe of $89.1 \mathrm{~mm}$ diameter. The average value of $9 \%$ of the reduction in the pipe compression loads when the pipe height is increased from $100 \mathrm{~mm}$ to $600 \mathrm{~mm}$ and a maximum reduction value of $11 \%$ occur with pipe thickness of $6.4 \mathrm{~mm}$ (Fig. 9).

The effect of the pipe thickness and height on the load-displacement relation is presented in Fig. 10. No Euler buckling was observed for all pipe specimens heights for this pipe diameter. 


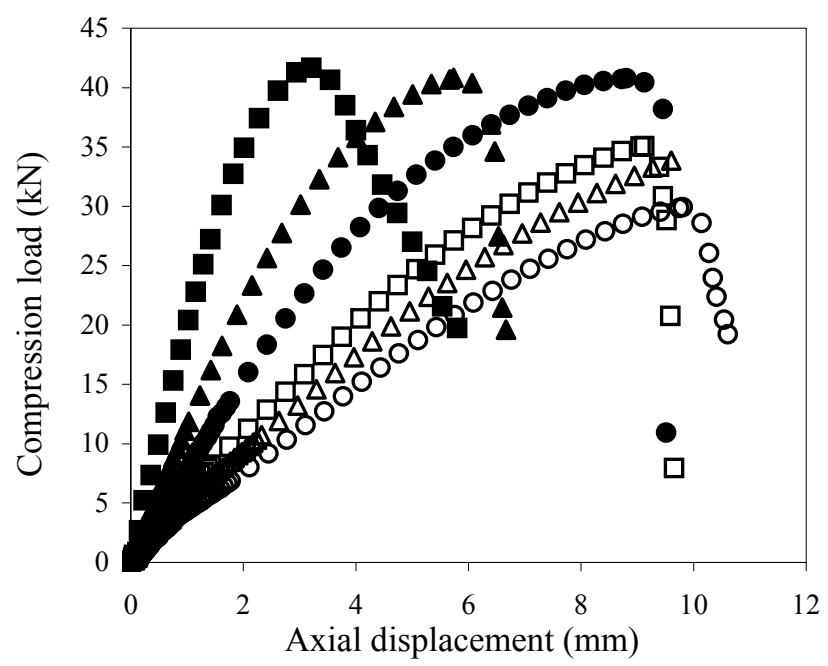

\begin{tabular}{|c|c|}
\hline $\begin{array}{c}\text { Pipe } \\
\text { height } \\
(\mathrm{mm})\end{array}$ & Symbol \\
\hline 100 & $\boldsymbol{\square}$ \\
\hline 200 & $\boldsymbol{\Delta}$ \\
\hline 300 & $\bullet$ \\
\hline 400 & $\square$ \\
\hline 500 & $\Delta$ \\
\hline 600 & $\circ$ \\
\hline
\end{tabular}

Fig. 7: Load-displacement relationship for the pipe with $89.1 \mathrm{~mm}$ diameter

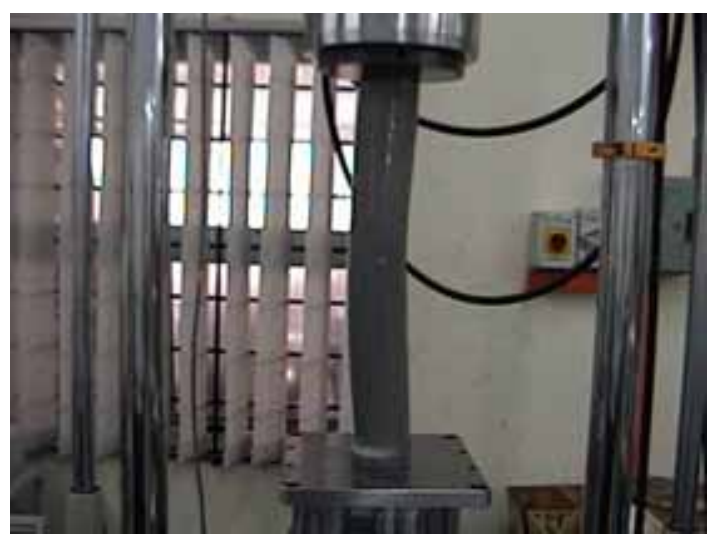

Fig. 8: Buckling occurring with long pipe specimens

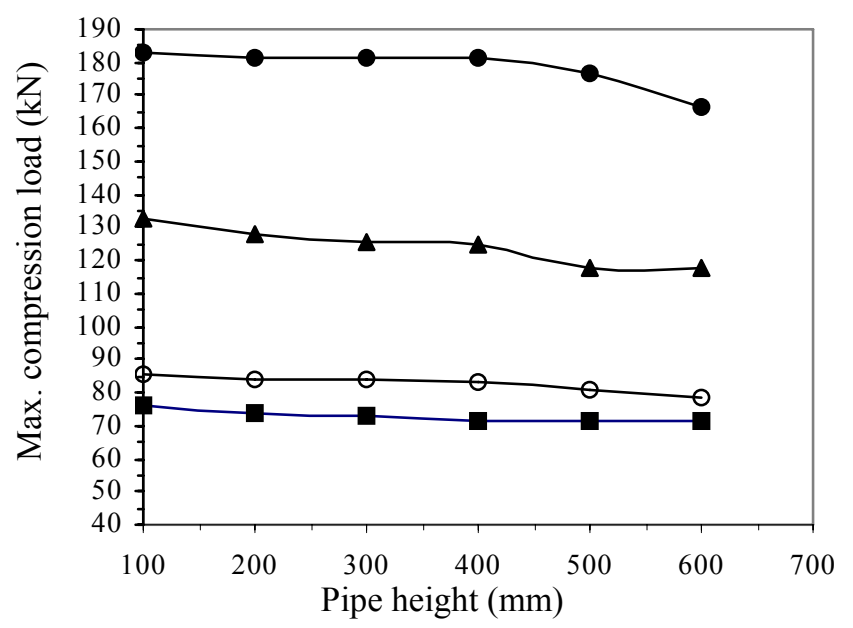

\begin{tabular}{|c|c|c|}
\hline $\begin{array}{c}\text { Pipe } \\
\text { Dia. } \\
(\mathrm{mm})\end{array}$ & $\begin{array}{c}\text { Pipe } \\
\text { thick. } \\
(\mathrm{mm})\end{array}$ & Symbol \\
\hline \multirow{4}{*}{114.3} & 4.0 & $\mathbf{\square}$ \\
\cline { 2 - 3 } & 4.7 & $\circ$ \\
\cline { 2 - 3 } & 6.4 & $\mathbf{\Delta}$ \\
\cline { 2 - 3 } & 9.5 & $\bullet$ \\
\hline
\end{tabular}

Fig. 9: Effect of the pipe height and thickness on the maximum compression load 152 


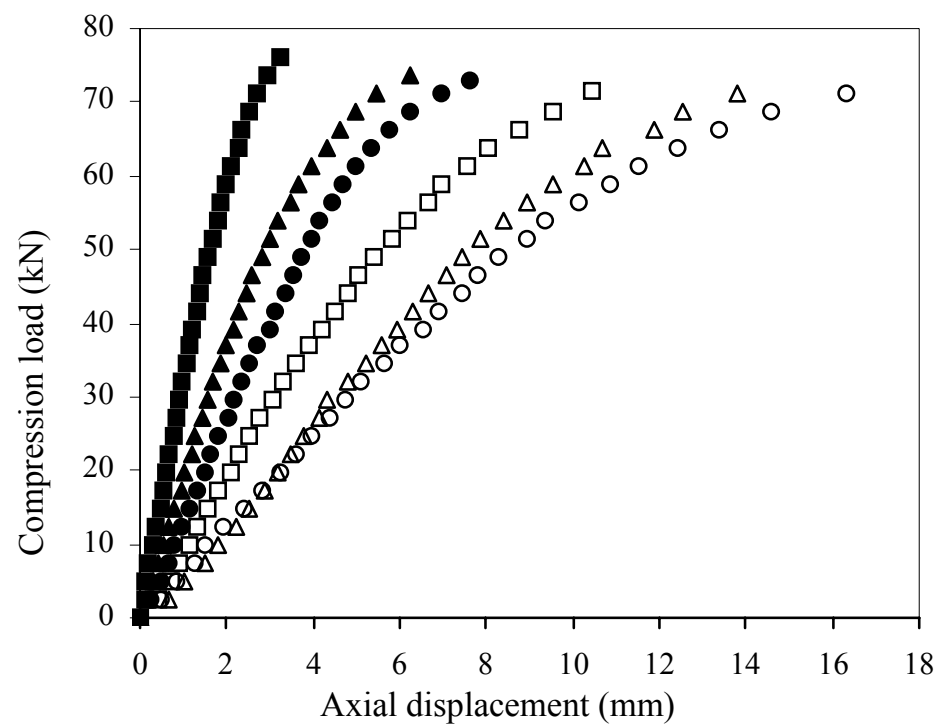

\begin{tabular}{|c|c|}
\hline $\begin{array}{c}\text { Pipe } \\
\text { height } \\
(\mathrm{mm})\end{array}$ & Symbol \\
\hline 100 & 口 \\
\hline 200 & $\boldsymbol{\Delta}$ \\
\hline 300 & $\bullet$ \\
\hline 400 & $\square$ \\
\hline 500 & $\Delta$ \\
\hline 600 & $\circ$ \\
\hline
\end{tabular}

Fig. 10: Load-displacement relation of the pipe with $114.3 \mathrm{~mm}$ diameter

\subsection{Theoretical results}

\subsubsection{Classical formula and FEA}

Results of computed on stresses, vertical and radial displacements of the pipe specimens due to an axial compression load of $3.4 \mathrm{kN}$ using Equations (A.1), (A.2), and (A.3) and the FEA are shown in the appendix A (Tables A.1 and A.2). The average and the maximum absolute differences of the axial displacements of all the pipe specimens by using Equation (A.2) and the FEA were $0.91 \%$ and $4 \%$, respectively.

These results prove that, Equation (A.2) is applicable to predict the vertical displacements of the pipe specimens subjected to an axial compression load even if the ratio of $R / t$ below the value of 10. But the average and the maximum value of the absolute differences of the radial displacements of all the pipe specimens by using Equation (A.3) and the FEA were $15.75 \%$ and $23.61 \%$ respectively. This may be due the effect of the pipe constraint, state of load (compression), and the ratio of $R / t$ of some specimens is less than 10 .

On the other hand, Equation (A.1) underestimates the values of the maximum stress along the pipe and does not give any idea for the stress distribution along the pipe due to the effect of the constraint on the pipe bottom. FEA demonstrates that, the stress concentration will develop at the pipe bottom and with values greater than that of Equation (A.1).

\subsubsection{Pipes behavior using FEA}

The behavior of the pipes under an axial uniform compression load is investigated by using the FEA techniques. A case of a pipe specimen (114.3 $\mathrm{mm}$ external diameter, $4 \mathrm{~mm}$ wall thickness and $300 \mathrm{~mm}$ height) was selected and subjected to an axial compression load of $3.4 \mathrm{kN}$. The stresses and displacements were determined and illustrated by the Figs. 11, 14, and 15.

Figure 11 shows that, the vertical stress distribution $\sigma_{z}$ is approximately constant along the pipe height (approximately $2306 \mathrm{kN} / \mathrm{m}^{2}$ ) but a maximum stress of $3532 \mathrm{kN} / \mathrm{m}^{2}$ developed at the external wall of the pipe bottom and a minimum stress of $1326 \mathrm{kN} / \mathrm{m}^{2}$ at the internal wall of 
pipe bottom. Due to the stress concentration around the external wall of the pipe bottom, the failure of the pipe is expected to occur at this location as local buckling. This result was verified by the experimental tests of the pipe specimens and was found that most of specimens failed at the pipe bottom as local buckling (Figs. 12 and 13).

The values of the stress at the radial direction $\left(\sigma_{x}\right.$ or $\left.\sigma_{y}\right)$ is approximately constant (approximately $169.459 \mathrm{kN} / \mathrm{m}^{2}$ ) along the pipe height and is also maximum on the external wall of the bottom of the pipe with a value of $1890 \mathrm{kN} / \mathrm{m}^{2}$, which is lower than $\sigma_{z}$ (Fig. 14).

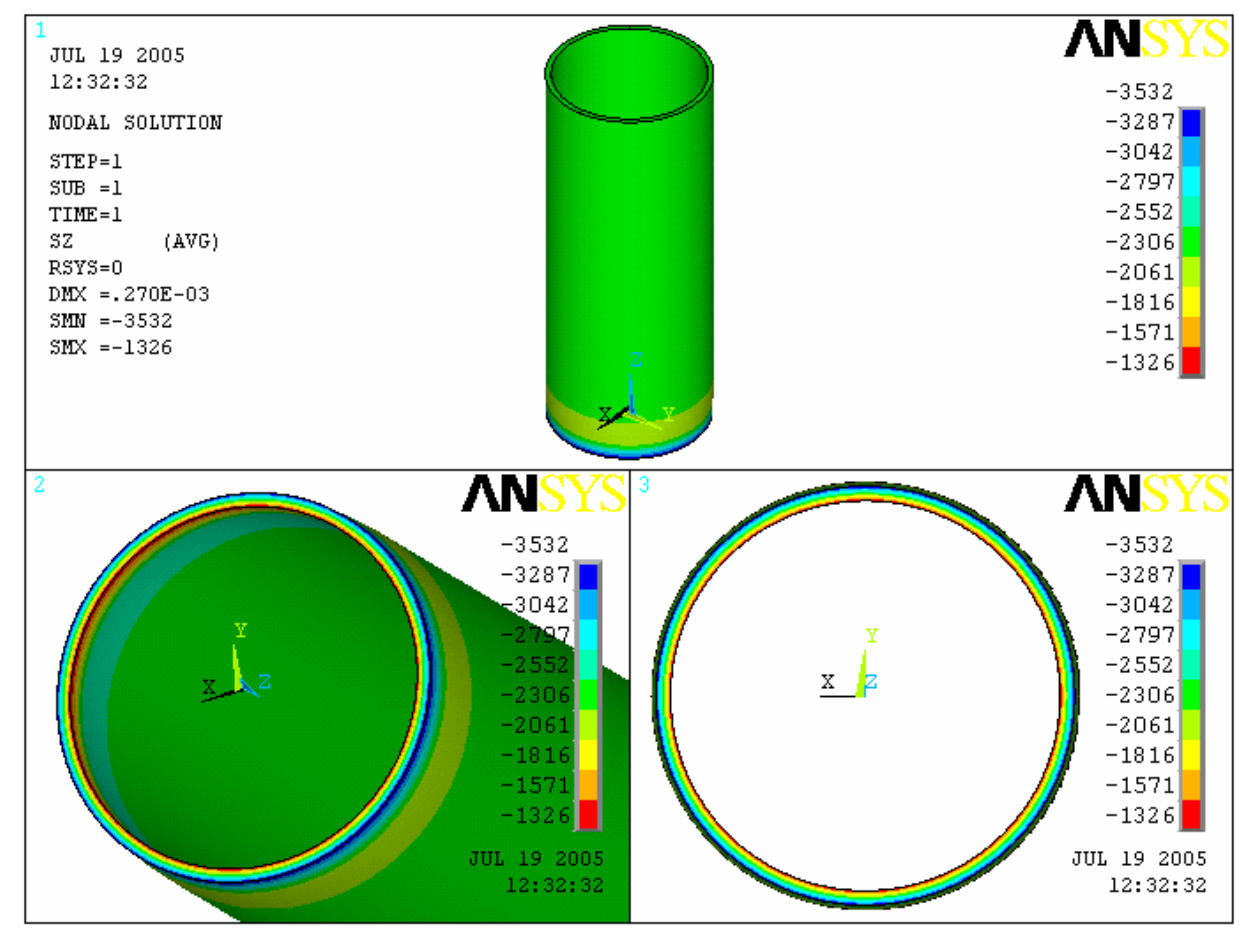

Fig. 11: Vertical stress distribution along the pipe wall height, $\sigma_{z}$

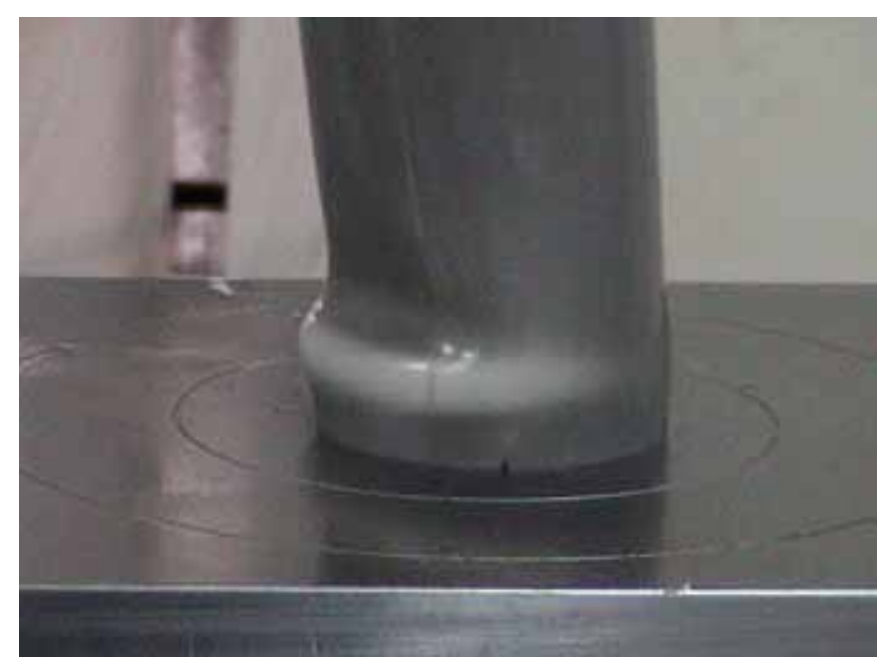

Fig. 12: Pipe specimen failed at the bottom 


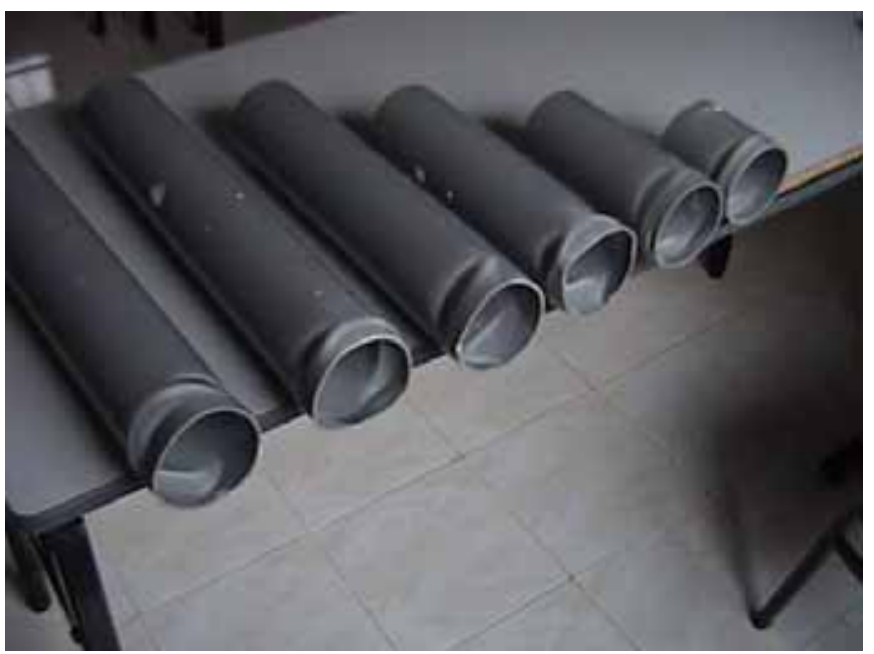

Fig. 13: Most of the pipe specimens failed at the bottom as local buckling

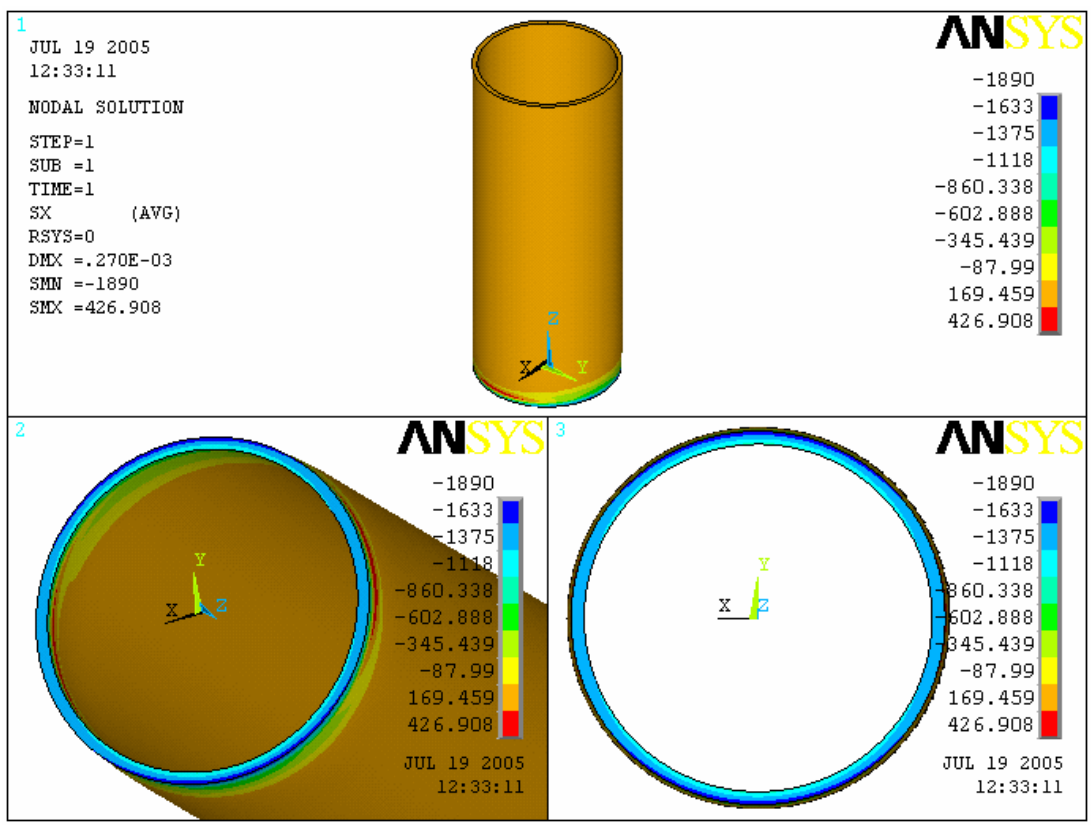

Fig. 14: Radial stress distribution along the pipe wall height, $\sigma_{x}$

The axial displacements $\Delta L$ of the pipe wall is shown in Fig. 15(a). Figure 15(b) and Fig. 15(c) shows the radial displacements $\Delta R$ in the pipe wall ( $x$ direction). The values of $0.27 \mathrm{~mm}$ and $0.02 \mathrm{~mm}$ as maximum axial and radial displacements respectively were developed. The radial displacement is in the direction outward of the pipe center and Fig. 15(c) shows the pipe position before (dashed line) and after the applying the load.

\subsection{Comparison between the experimental and FEA results}

Comparison between the experimental results and those obtained from the theoretical analysis by FEA for some selected cases of pipe specimens of diameter $89.1 \mathrm{~mm}$ and $114.3 \mathrm{~mm}$ are 
shown in Figs. 16 and 17, respectively. In general it was found that in the elastic range of loads a good agreement between the theoretical and experimental results for all the pipe specimens were obtained.

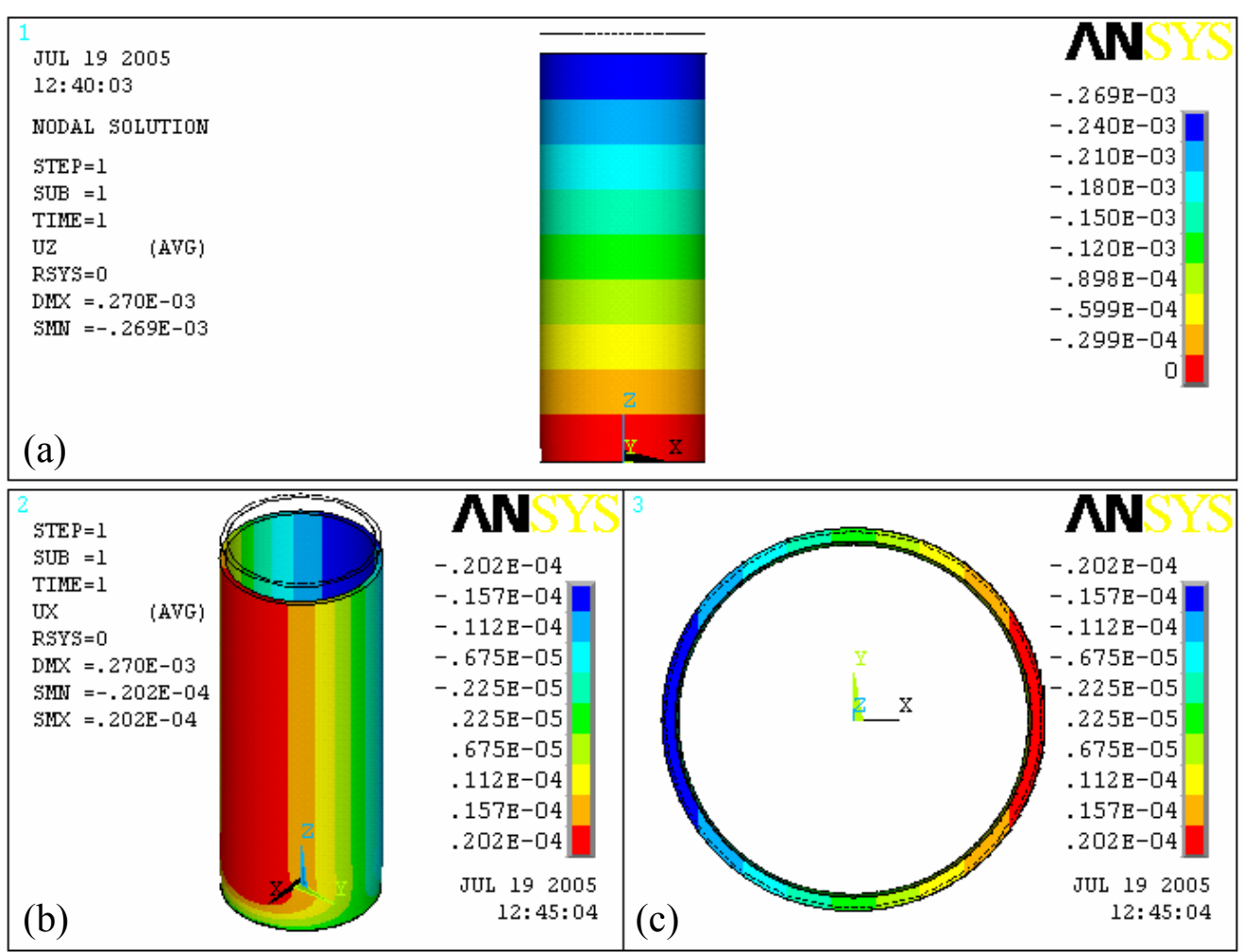

Fig. 15: Axial and radial displacements in the pipe wall

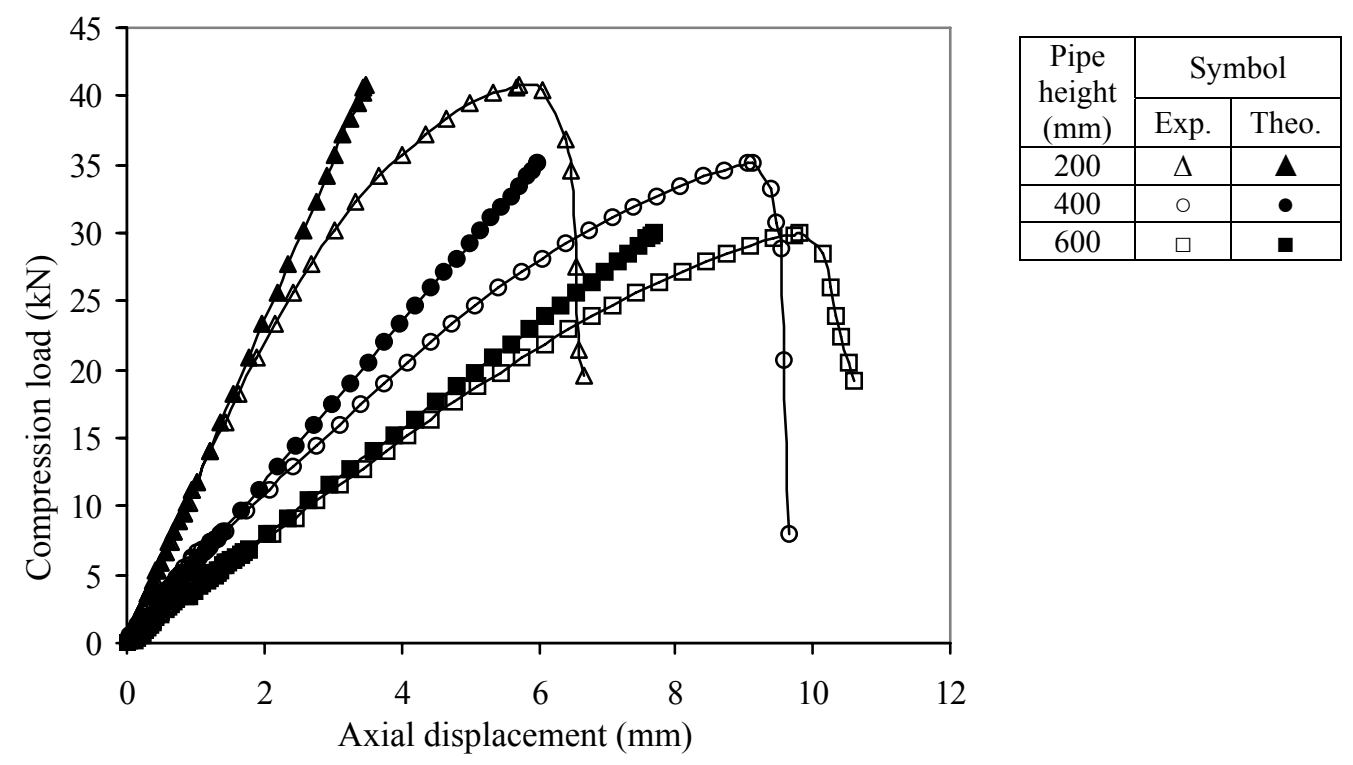

Fig. 16: Experimental and theoretical results of the $89.1 \mathrm{~mm}$ diameter pipe specimen tests 156 


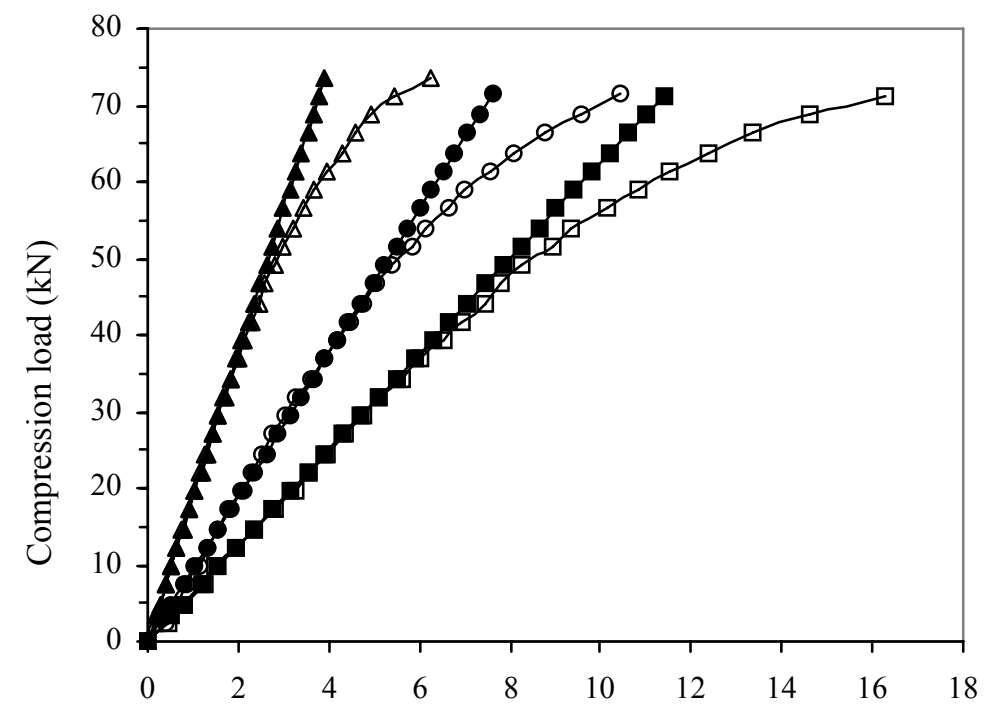

\begin{tabular}{|c|c|c|}
\hline Pipe & \multicolumn{2}{|c|}{ Symbol } \\
\cline { 2 - 3 } height \\
\cline { 2 - 3 }$(\mathrm{mm})$ & Exp. & Theo. \\
\hline 200 & $\Delta$ & $\boldsymbol{\Delta}$ \\
\hline 400 & $\circ$ & $\bullet$ \\
\hline 600 & $\square$ & - \\
\hline
\end{tabular}

Axial displacement (mm)

Fig. 17: Experimental and theoretical results of the $114.3 \mathrm{~mm}$ diameter pipe specimen tests

\section{CONCLUSION}

The collapse of axially loaded PVC-U pipes was investigated experimentally to evaluate the capability of the pipe to be used as a subsurface water storage, which is required to support an axial load of $3.4 \mathrm{kN}$. Short-term axial compression tests of the specimens demonstrate that, the PVC-U pipes have a capability to support axial static load of more than $3.4 \mathrm{kN}$.

In general it was found that, a reduction in the maximum load that the pipe can support occurs when the pipe height is increased and this reduction is lower with greater pipe diameter. Increasing the pipe thickness and diameter increases the pipe strength.

Euler buckling was observed in the pipe specimens with a diameter of $89.1 \mathrm{~mm}$ and height of $500 \mathrm{~mm}$ and $600 \mathrm{~mm}$ but it was not observed with a diameter of $114.3 \mathrm{~mm}$ for all the pipe specimen heights.

Finite element analysis of the pipe specimens reveal that, the stress concentrates around the bottom of specimens when applying an axial load and this gives an explanation for the reason of failure of most specimens at this location in the experimental tests. Good agreement was found between the experimental results and those obtained from the theoretical analysis by using the classical formulas and the finite element analysis.

\section{REFERENCES}

1. Dutta, P.K. and Vaidya, U. (2003), A study of the long-term applications of vinyl sheet piles, U.S. Army Corps of Engineers, Engineer Research and Development Center, Cold Regions Research and Engineering Laboratory.

2. Mersiowsky, D.I., Stegmann, I.R., Ejlertsson, J., and Svensson, B. (1999), Long-term behaviour of pvc products under soil-buried and landfill conditions - final report of the 
research project, Dept. of Waste Management, Technical University of Hamburg-Harburg, Germany and Dept. of Water and Environmental Studies, Linkping University, Sweden..

3. Titow, W.V. (1990), PVC plastics properties, processing, and applications, Elsevier science publishers LTD, England.

4. Reala, L.P., Pereira, A.R., and Gardetteb, J. (2002), Artificial accelerated weathering of poly(vinyl chloride) for outdoor applications: the evolution of the mechanical and molecular properties, Polymer Degradation and Stability, vol. 82, pp. 235-243.

5. Mamalis, A.G., Manolakos, D.E., Viegelahn, G.L., Vaxevanidis, N.M., and Johnson, W. (1986a), The inextensional collapse of grooved thin-walled cylinders of PVC under axial loading, Int. J. Impact Engng, vol. 4(1), pp. 41-56.

6. Mamalis, A.G., Manolakos, D.E., Viegelahn, G.L., Vaxevanidis, N.M., and Johnson, W. (1986b), On the inextensional axial collapse of thin PVC conical shells, Int. J. Impact Engng, vol. 4(1), pp. 41-56.

7. Mamalis, A.G., Manolakos, D.E., and Viegelahn, G.L. (1989), The axial crushing of thin PVC tubes and frusta of square cross-section, Int. J. Impact Engng, vol. 8(3), pp. 241-264.

8. Grzebieta, R.H. (1990), An alternative method for determining the behavior of round stocky tubes subjected to an axial crush load, Thin-Walled Structures, vol. 9(1-4), pp. 61-89.

9. Kormi, K., Webb, D.C., and Johnson, W. (1993), The crash response of circular tubes under general applied loading, International Journal of impact Engineering, vol. 13(2), pp. 243257.

10. Gupta, N.K. and Velmurugan, R. (1995), An analysis of axi-symmetrie axial collapse of round tubes, Thin-Walled Structures, vol. 22(4) pp. 261-274.

11. Mamalis, A.G., Manolakos, D.E., Demosthenous, G.A., and Ioannidis, M.B. (1996), Analysis of failure mechanisms observed in axial collapse of thin-wailed circular fibreglass composite tubes, Thin-Walled Structures, vol. 24(4), pp. 335-352.

12. Gupta, N.K. (1998), Some aspects of axial collapse of cylindrical thin-walled tubes, ThinWalled Structures, vol. 32(1-3), pp. 111-126.

13. Singace, A.A. (2000), Collapse behaviour of plastic tubes filled with wood sawdust, ThinWalled Structures, vol. 37(2), pp. 163-187.

14. Gupta, N.K. and Abbas, H. (2000), Mathematical modeling of axial crushing of cylindrical tubes. Thin-Walled Structures, vol. 38(4), pp. 355-375.

15. Gupta, N.K., Abbas, H., and Venkatesh (2001), Some considerations in axisymmetric folding of metallic round tubes, International Journal of impact Engineering, vol. 25(4), pp. 331-344.

16. Daneshi, G.H. and Hosseinipour, S.J. (2002), Elastic-plastic theory for initial buckling load of thin-walled grooved tubes under axial compression, Journal of Materials Processing Technology, vol. (125-126), pp. 826-832.

17. Bardi, F.C., Yun, H.D., and Kyriakides, S. (2003), On the axisymmetric progressive crushing of circular tubes under axial compression, International Journal of Solids and Structures, vol. 40(12), pp. 3137-3155.

18. Hosseinipour, S.J. and Daneshi, G.H. (2003), Energy absorption and mean crushing load of thin-walled grooved tubes under axial compression, Thin-Walled Structures, vol. 41(1), pp. $31-46$. 
19. Mahdi, E., Hamouda, A.M.S., Sahari, B.B., and Khalid, Y.A. (2003), On the collapse of cotton/epoxy tubes under axial static loading, Applied Composite Materials, vol. 10(2), pp. 67-84.

20. Al Galib, D. and Limam, A. (2004), Experimental and numerical investigation of static and dynamic axial crushing of circular aluminum tubes, Thin-Walled Structures, vol. 42(8), pp. 1103-1137.

21. Hosseinipour, S.J., and Daneshi, G.H. (2004), Experimental studies on thin-walled grooved tubes under axial compression, Society for Experimental Mechanics, vol. 44(1), pp. 101108.

22. Murase, K. and Wada, H. (2004), Numerical study on the transition of plastic buckling modes for circular tubes subjected to an axial impact load, International Journal of impact Engineering, vol. 30(8-9), pp. 1131-1146.

23. Gupta, N.K., Abbas, H., and Venkatesh (2005), Considerations in straight fold analysis of thin tubes under axial compression, International Journal of impact Engineering, vol. 31(8), pp. 1039-1053.

24. American Society of Civil Engineers (ASCE) (1992), Design and Construction of Urban Stormwater Management Systems, Manuals and Reports of Engineering Practice, No. 77, VA., USA.

25. Paling Industries Sdn Bhd., Malaysia (2005), http://www.paling.com.my. Accessed on 10 January 2005.

26. Young, W.C. and Budyanas, R.G. (2002), Roark's Formulas for Stress and Strain, 7th ed., McGraw Hill, New York.

27. ANSYS, Inc. (2004), Ansys Release 9.0 documentation.

\section{APPENDIX A}

The formulas related to a cylindrical vessel with internal radius $R$, thickness $t$ and height $L$ and subjected to an axial tension load are,

$$
\begin{gathered}
\sigma_{z}=\frac{p}{t} \\
\sigma_{c}=0 \\
\Delta L=\frac{p L}{E t} \\
\Delta R=\frac{p v R}{E t}
\end{gathered}
$$

where, $\sigma_{z}$ is the longitudinal or axial stress, $\sigma_{c}$ the circumferential, or hoop, stress, $p$ the uniform axial load per unit length, $E$ the modulus of elasticity, $\Delta L$ the axial displacement, $v$ the poisson's ratio, and $\Delta R$ is the radial displacement. 
Table A.1: Theoretical results of $89.1 \mathrm{~mm}$ pipe diameter

\begin{tabular}{|c|c|c|c|c|c|c|c|c|c|}
\hline \multirow[b]{2}{*}{$\begin{array}{c}\text { Pipe } \\
\text { diamete } \\
(\mathrm{mm})\end{array}$} & \multirow[b]{2}{*}{$\begin{array}{c}\text { Pipe } \\
\text { thickness } \\
(\mathrm{mm})\end{array}$} & \multirow[b]{2}{*}{$\begin{array}{c}\text { Pipe } \\
\text { height } \\
(\mathrm{mm})\end{array}$} & \multirow[b]{2}{*}{$R / t$} & \multicolumn{3}{|c|}{ Classical formula } & \multicolumn{3}{|c|}{ ANSYS FEA results } \\
\hline & & & & $\begin{array}{c}\text { Stress } \\
\left(\mathrm{kN} / \mathrm{m}^{2}\right)\end{array}$ & $\begin{array}{c}\text { Vertical } \\
\text { displacement } \\
(\mathrm{mm})\end{array}$ & $\begin{array}{c}\text { Radial } \\
\text { displacement } \\
(\mathrm{mm})\end{array}$ & $\begin{array}{c}\text { Max. } \\
\text { Stress } \\
\left(\mathrm{kN} / \mathrm{m}^{2}\right)\end{array}$ & $\begin{array}{c}\text { Vertical } \\
\text { displacement } \\
(\mathrm{mm})\end{array}$ & $\begin{array}{c}\text { Radial } \\
\text { displacement } \\
(\mathrm{mm})\end{array}$ \\
\hline \multirow{24}{*}{89.1} & \multirow{6}{*}{3.2} & 100 & 12.92 & 3919 & 0.15 & 0.0225 & 5497 & 0.144 & 0.0254 \\
\hline & & 200 & 12.92 & 3919 & 0.29 & 0.0225 & 5497 & 0.288 & 0.0254 \\
\hline & & 300 & 12.92 & 3919 & 0.44 & 0.0225 & 5497 & 0.433 & 0.0254 \\
\hline & & 400 & 12.92 & 3919 & 0.58 & 0.0225 & 5497 & 0.578 & 0.0254 \\
\hline & & 500 & 12.92 & 3919 & 0.73 & 0.0225 & 5497 & 0.723 & 0.0254 \\
\hline & & 600 & 12.92 & 3919 & 0.87 & 0.0225 & 5497 & 0.868 & 0.0254 \\
\hline & \multirow{6}{*}{3.8} & 100 & 10.72 & 3323 & 0.12 & 0.0188 & 4708 & 0.118 & 0.0215 \\
\hline & & 200 & 10.72 & 3323 & 0.25 & 0.0188 & 4708 & 0.248 & 0.0215 \\
\hline & & 300 & 10.72 & 3323 & 0.37 & 0.0188 & 4708 & 0.366 & 0.0215 \\
\hline & & 400 & 10.72 & 3323 & 0.49 & 0.0188 & 4708 & 0.487 & 0.0215 \\
\hline & & 500 & 10.72 & 3323 & 0.62 & 0.0188 & 4708 & 0.619 & 0.0215 \\
\hline & & 600 & 10.72 & 3323 & 0.74 & 0.0188 & 4708 & 0.733 & 0.0215 \\
\hline & \multirow{6}{*}{5.0} & 100 & 7.91 & 2562 & 0.09 & 0.0141 & 3680 & 0.089 & 0.0165 \\
\hline & & 200 & 7.91 & 2562 & 0.19 & 0.0141 & 3680 & 0.19 & 0.0165 \\
\hline & & 300 & 7.91 & 2562 & 0.28 & 0.0141 & 3680 & 0.282 & 0.0165 \\
\hline & & 400 & 7.91 & 2562 & 0.38 & 0.0141 & 3680 & 0.382 & 0.0165 \\
\hline & & 500 & 7.91 & 2562 & 0.47 & 0.0141 & 3680 & 0.473 & 0.0165 \\
\hline & & 600 & 7.91 & 2562 & 0.57 & 0.0141 & 3680 & 0.571 & 0.0165 \\
\hline & \multirow{6}{*}{6.1} & 100 & 6.30 & 2128 & 0.08 & 0.0114 & 3082 & 0.0768 & 0.0137 \\
\hline & & 200 & 6.30 & 2128 & 0.16 & 0.0114 & 3082 & 0.156 & 0.0137 \\
\hline & & 300 & 6.30 & 2128 & 0.24 & 0.0114 & 3082 & 0.234 & 0.0137 \\
\hline & & 400 & 6.30 & 2128 & 0.32 & 0.0114 & 3082 & 0.313 & 0.0137 \\
\hline & & 500 & 6.30 & 2128 & 0.39 & 0.0114 & 3082 & 0.392 & 0.0137 \\
\hline & & 600 & 6.30 & 2128 & 0.47 & 0.0114 & 3082 & 0.471 & 0.0137 \\
\hline
\end{tabular}

Table A.2: Theoretical results of $114.3 \mathrm{~mm}$ pipe diameter

\begin{tabular}{|c|c|c|c|c|c|c|c|c|c|}
\hline \multirow[b]{2}{*}{$\begin{array}{c}\text { Pipe } \\
\text { diameter } \\
(\mathrm{mm})\end{array}$} & \multirow[b]{2}{*}{$\begin{array}{c}\text { Pipe } \\
\text { thickness } \\
(\mathrm{mm})\end{array}$} & \multirow[b]{2}{*}{$\begin{array}{l}\text { Pipe } \\
\text { height } \\
(\mathrm{mm})\end{array}$} & \multirow[b]{2}{*}{$R / t$} & \multicolumn{3}{|c|}{ Classical formula } & \multicolumn{3}{|c|}{ ANSYS FEA results } \\
\hline & & & & $\begin{array}{c}\text { Stress } \\
\left(\mathrm{kN} / \mathrm{m}^{2}\right)\end{array}$ & $\begin{array}{c}\text { Vertical } \\
\text { displacement } \\
(\mathrm{mm})\end{array}$ & $\begin{array}{c}\text { Radial } \\
\text { displacement } \\
(\mathrm{mm})\end{array}$ & $\begin{array}{c}\text { Max. } \\
\text { Stress } \\
\left(\mathrm{kN} / \mathrm{m}^{2}\right) \\
\end{array}$ & $\begin{array}{c}\text { Vertical } \\
\text { displacement } \\
(\mathrm{mm})\end{array}$ & $\begin{array}{c}\text { Radial } \\
\text { displacement } \\
(\mathrm{mm}) \\
\end{array}$ \\
\hline \multirow{24}{*}{114.3} & \multirow{6}{*}{4.0} & 100 & 13.29 & 2442 & 0.09 & 0.018 & 3532 & 0.090 & 0.0202 \\
\hline & & 200 & 13.29 & 2442 & 0.18 & 0.018 & 3532 & 0.180 & 0.0202 \\
\hline & & 300 & 13.29 & 2442 & 0.27 & 0.018 & 3532 & 0.270 & 0.0202 \\
\hline & & 400 & 13.29 & 2442 & 0.36 & 0.018 & 3532 & 0.360 & 0.0202 \\
\hline & & 500 & 13.29 & 2442 & 0.45 & 0.018 & 3532 & 0.450 & 0.0202 \\
\hline & & 600 & 13.29 & 2442 & 0.54 & 0.018 & 3532 & 0.541 & 0.0202 \\
\hline & \multirow{6}{*}{4.7} & 100 & 11.16 & 2091 & 0.08 & 0.015 & 3049 & 0.081 & 0.0173 \\
\hline & & 200 & 11.16 & 2091 & 0.15 & 0.015 & 3049 & 0.152 & 0.0173 \\
\hline & & 300 & 11.16 & 2091 & 0.23 & 0.015 & 3049 & 0.230 & 0.0173 \\
\hline & & 400 & 11.16 & 2091 & 0.31 & 0.015 & 3049 & 0.313 & 0.0173 \\
\hline & & 500 & 11.16 & 2091 & 0.39 & 0.015 & 3049 & 0.389 & 0.0173 \\
\hline & & 600 & 11.16 & 2091 & 0.46 & 0.015 & 3049 & 0.461 & 0.0173 \\
\hline & \multirow{6}{*}{6.4} & 100 & 7.93 & 1560 & 0.06 & 0.011 & 2302 & 0.062 & 0.0129 \\
\hline & & 200 & 7.93 & 1560 & 0.12 & 0.011 & 2302 & 0.120 & 0.0129 \\
\hline & & 300 & 7.93 & 1560 & 0.17 & 0.011 & 2302 & 0.172 & 0.0129 \\
\hline & & 400 & 7.93 & 1560 & 0.23 & 0.011 & 2302 & 0.233 & 0.0129 \\
\hline & & 500 & 7.93 & 1560 & 0.29 & 0.011 & 2302 & 0.292 & 0.0129 \\
\hline & & 600 & 7.93 & 1560 & 0.35 & 0.011 & 2302 & 0.347 & 0.0129 \\
\hline & \multirow{6}{*}{9.5} & 100 & 5.02 & 1082 & 0.04 & 0.007 & 1650 & 0.0388 & 0.0089 \\
\hline & & 200 & 5.02 & 1082 & 0.08 & 0.007 & 1650 & 0.0810 & 0.0089 \\
\hline & & 300 & 5.02 & 1082 & 0.12 & 0.007 & 1650 & 0.123 & 0.0089 \\
\hline & & 400 & 5.02 & 1082 & 0.16 & 0.007 & 1650 & 0.161 & 0.0089 \\
\hline & & 500 & 5.02 & 1082 & 0.20 & 0.007 & 1650 & 0.202 & 0.0089 \\
\hline & & 600 & 5.02 & 1082 & 0.24 & 0.007 & 1650 & 0.239 & 0.0089 \\
\hline
\end{tabular}

